\title{
熱影響部の最高硬さの予測式の提 案*
}

\author{
寺崎 俊夫**, 野村 卓司***, 北田 豊文****
}

\author{
Proposal of Predictive Equation for Maximum Hardness in the \\ Heat-Affected-zone*
}

\author{
by Toshio Terasaki**, Takuji Nomura*** and Toyofumi Kitada****
}

\begin{abstract}
This paper deals with the predictive equation for obtaining a maximum hardness in the heat-affectedzone. The estimating equation was derived using the kinetics of phase transformation and the theory of heat transfer. The material constants included in the equation were determined from hardness data of CCT-diagram by the stepwise multiple regression analyses. The predictive equation was proved to be more reliable than other formulae by comparing with data of hardness reported by many researchers.
\end{abstract}

Key Words: Heat-affected-zone, Maximum Hardness, Predictive Equation, CCT-diagram

\section{1. 緒言}

溶接熱影幚部の最高便さは溶接低温割れ"，腐食強 度2゙などに関連した溶接性を評価する重要な指標となっ ている，溶接熱影幚部の硬さを予測する研究は多くの研 究者により行なわれている ${ }^{3-12)}$, Dearden, O'Neill ${ }^{3)}$, 田村 ${ }^{4}$, 別所

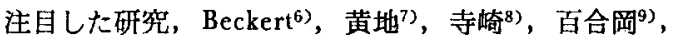

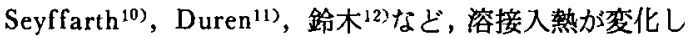
てあ啸さが予測できる事を示した研究などがある。とこ ろで，これまでに報告された研究では硬さの変化曲楾の 䦭数形が仮定されており，治金の分野における研究成果 を基礎にして論じられていない，一方，冶金の分野にお いては鋼の焼入れ性に関する研究は多くなされており， 種々の知兒が報告されている13-14).

本研究では治金分野における変態速度論 ${ }^{15}$ に注目し て, 硬さの変化曲線を理論的に導き, 導加れた式の定数 を溶接用の CCT 図を利用して決定することにより，従 来から提案されている硬さ予測式よりす精度の良い式を 提案した。

\section{2. 硬さ予測式と変热速度論}

溶接熱影揰部の最高硬さ $H_{V}$ とマルテンサイト量 $M$ の関係は Duren ${ }^{113}$ が示しているように線形の式が一般 に成立している。

$$
\begin{array}{cc}
H_{V}=H_{V \mu} M & +H_{V 0}(1-M) \\
\text { ただし, } H_{V M}: & \text { マルテンサイト }(M) \text { が } 1(100 \%) \text { の } \\
& \text { 時の硬さ } \\
H_{V 0}: & M=0 \text { の時の硬さ }
\end{array}
$$

溶接熱影篦部の硬さとマルテンサイトの関係を Fig. 1 亿 示す. Fig.1 の硬さの奏噱值は稻垣が求めた CCT 図の データである ${ }^{16)}$. 横軸は 1-Mでマルテンサイト以外の 組織の割合を示している。図より硬さは式(1)に示すよう

\footnotetext{
*原稿受付 昭和62年 3 月14日 明和58年度秋季全国大会及び昭和62 年 5 月溶接绐金研究委員会で発表 (WM-1154-87)

**正員 九州工業大学 Member, Kyushu Institute of Technology

***非 会員 九州工業大学 (学生) Kyushu Institute of Techno$\log y$

****正 員 日本鋼管(怢) Member, Nippon Kokan Co
}

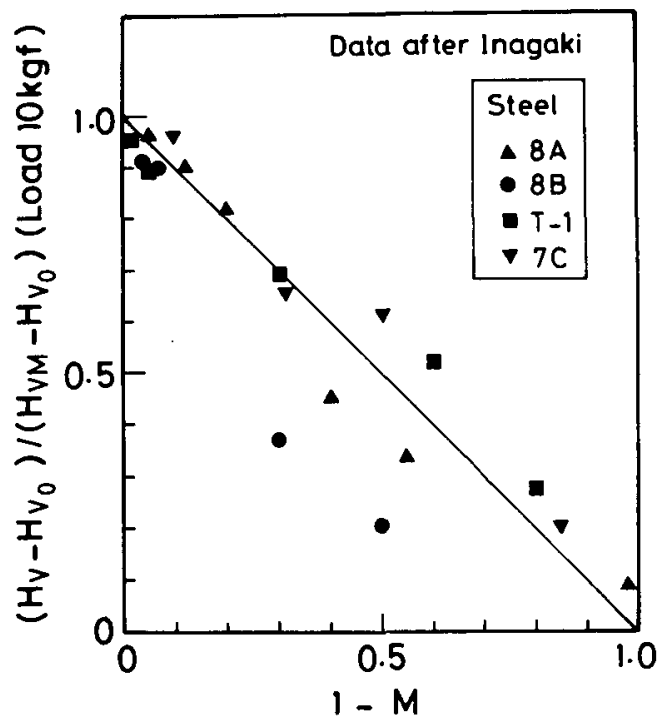

Fig. 1 Relation between hardness and martensite fraction

にマルテントサイトの含有率 $M$ でおおむね決定されて いることになる.

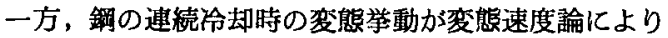
取り扱われている ${ }^{14,18)}$. 変態速度碖を用いると連続冷却 後の拡散変態生成物（ベイナイト，パーライトなよ゙）が 計算できるため, マルテンサイトの含有率が求められ る. そこで, 著者らは梅本 ${ }^{(4)}$ の手法に従って, マルテン サイトの含有率を変態速度論より埒き, 硬さ予測式を導 Wた.

梅本の手法は等溫変態速度式とScheil ${ }^{19)}$ の加算則の 修正式を組み合わせている，应散変態生成物の变熊率を $X$ とすると, 等温変態速度は炏式の Johnson-Mehl 夕 イプの式で表現できる。

$$
\begin{aligned}
& X=1-\exp \left\{-f(T) \cdot t(T)^{n}\right\} \\
& \text { ただし， } f(T) \text { : 反応速度定数 } n \text { : 時間指数 } \\
& t(T) \text { : 等温保持時間 } T \text { : 等温保持温度 }
\end{aligned}
$$

Fig. 2 は梅本の加算則を説明する図である。TTT 図の 


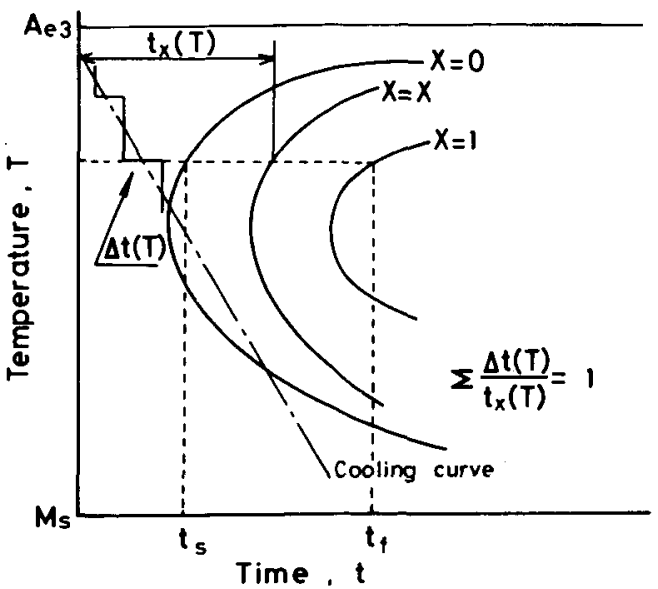

Fig. 2 TTT diagram, cooling curve and additivity rule

拡散変熊開始曲線 $(X=0)$, 変態終了曲線 $(X=1)$ 以外 に変熊率 $X$ の曲線を引き, 埧度 $T$ での変熊率が $X$ に なるのに要する時間を $t_{x}(T)$ 上する。一点鎖線の連続冷 却曲線を各温度での微小冷却時間 $\Delta t(T)$ 亿細分して, 次式が成立するときに，摭散生成物が $X$ 生じると考え ている.

$$
\sum_{T=A e_{3}}^{T_{0}} \frac{\Delta t(T)}{t_{x}(T)}=1 \text {, すなわち, } \int_{A_{e_{3}}}^{T_{0}} \frac{(d t / d T)}{t_{x}(T)} d T=1
$$

ただし，A $e_{3}$ : オーステナイトから拡散変態生成物が 生じる温度の上限温度

$T_{0}:$ オーステナイトから拡散変態生成物が 生じる温度の下限温度

式(3)の $t_{x}$ は式(2)の $t$ と同等であるから，式(2)より

$$
t_{x}(T)=[\ln \{1 /(1-X)\} / f(T)]^{1 / n}
$$

となり，式(3にに代入して，X について解くと

$$
X=1-\exp \left[-\left\{\int_{A_{3}}^{T_{0}} \frac{f(T)^{1 / n}}{d T / d t} d T\right\}^{n}\right]
$$

となる。

溶接金属部の泠却速度は移動熱源の式 ${ }^{20)}$ 上り次式の関 数形になる。

$$
-d T / d t=A g(Q) h(h) T^{m}
$$

ただし, $A=2 \pi \lambda, 2 \pi \lambda c \rho \quad g(Q)=Q, Q^{2} h(h)=1, h^{2}$ $m=2,3$

等号の後の文字はそれぞれ瞬間点熱源，瞬間 線熱源での值である。

$\lambda:$ 熱层導率 $c:$ 比熱 $\rho:$ 密度 $Q:$ 溶接入熱 $h:$ 板厚

溶接では $800^{\circ} \mathrm{C}$ から $500^{\circ} \mathrm{C}$ までの冷却時間 ( $\tau$ とする) が熱影繁部の組織々決定するためのパラメータとして用 いられるため、このパラメータを式(5)に道入すると

$$
-d T / d t=B / \tau \cdot T^{m}
$$

ただし $B=\left(1 / 500^{m-1}-1 / 800^{m-1}\right) \cdot\{1 /(m-1)\}$ とな る.

式(4)，(6)より拡散変態生成物 $X$ と冷却時間 て とは次 式で結び付けられる。

$$
X=1-\exp \left[-\left\{\tau / B \int_{T_{0}}^{\Delta e_{3}} f(T)^{1 / n} / T^{m} d T\right\}^{n}\right]
$$

拡散変態生成物が出現し始める $\tau$ を $\tau_{\boldsymbol{M}}$ と表すと

$$
\varepsilon=1-\exp \left[-\left\{\tau_{\boldsymbol{H}} / B \int_{T_{0}}^{A_{e_{3}}} f(T)^{1 / n} / T^{m} d T\right\}^{n}\right]
$$

ただし， $\varepsilon$ : 抬散変態生成物が検出できる最小の量で ある. 本論文では梅本らの研究と一致さ せて $\varepsilon=0.05$ とする.

式(7)，(8)上り糟分項が消去でき，次の式が得られる。

$$
1-X=\exp \left\{-\epsilon\left(\tau / \tau_{\boldsymbol{M}}\right)^{n}\right\}=\exp \left\{-0.05\left(\tau / \tau_{\boldsymbol{M}}\right)^{n}\right\}
$$

マルテンサイト量 $M=1-X$ と式(1)，(9)より硬さ予測 式として次式か將かれる。

$$
H_{\boldsymbol{V}}=\left(H_{V_{\mathcal{M}}}-H_{V_{0}}\right) \exp \left\{-0.05\left(\tau / \tau_{\boldsymbol{K}}\right)^{n}\right\}+H_{V_{0}}
$$

\section{CCT 図のテータ利用による硬さ予测式 の定数の決定}

\section{1回用分析手法}

日本で作成されて公表されている溶接用の CCT 図 102枚のデータを用いて，式(10)の硬さ予測式の定数 $H_{\boldsymbol{V}}$ ， $H_{V 0}, n, \tau_{M}$ 之化学成分を結び付けるために次に示す回 州分析の手法を用いた。

(1) Stepwise regression analysis を用いて応答変数 $\left(H_{V \boldsymbol{K}}, H_{V 0}, n, \tau_{\boldsymbol{K}}\right)$ と有意な関係にある独立変数（化 学成分）を選択する ${ }^{21)}$.

（2）選択された独立変数を種々の関数にして，応答変 数を最す良く説明できる独立変数の関数形を一般に使用 されている回偳分析手法に上り决定する。

（3）選択された独立変数の項を決定した後に，残りの 独立変数を用いて，(1)，(2)を繰り返す。

\section{2 回爆分析結果}

(1) 時間指数 $n$

式(10)より時間指数 $n$ は硬さ之次の式で結び付けられ る.

$$
\begin{aligned}
& \ln \left[\ln \left\{\left(H_{V K}-H_{V_{0}}\right) /\left(H_{V}-H_{V_{0}}\right)\right\}\right]=n \ln \tau \\
& \quad+\ln \left(0.05 / \tau_{\mathbf{M}}^{*}\right)
\end{aligned}
$$

式(11) より時間指数 $n$ は横軸に $\ln \tau$, 綎軸に $\ln [\ln$ $\left.\left\{\left(H_{V X}-H_{V 0}\right) /\left(H_{V}-H_{V 0}\right)\right\}\right]$ を取って, 得られる直線 の頋きとして与えられる。、ルテンサイト 100\%，0\% の硬さが明確に示されている45枚の CCT 図より求めた $n$ 値を回㷌分析した結果として次式が得られた。

$$
\begin{aligned}
\mathrm{n}= & 5.1 \mathrm{C}+1.7 \mathrm{Si}-0.39 \mathrm{Mn}+0.6 \mathrm{Ni}-1.3 \mathrm{Cr} \\
& -0.8 \mathrm{Mo}+6.4 \mathrm{~V}+3 \mathrm{Cu}-45 \mathrm{~B}+0.29 \\
& \left(\mathrm{R}^{2}=17.796\right)
\end{aligned}
$$

ただし，化学成分の単位はvt\%である。

Fig. 3 は $n$ 值の頻度分布である。回佩分析に上り求め られた予測式で実測值が説明できる割合を示している重 相関係数 $R^{2}$ 加17.796 上小さい事上り，化学成分之 $n$ 値 に強い相関関係がないてとになる。この原团として炊の 事が考えられる。熱影帮部の組糡はベイナイト，フェラ イト，パーライトなどの複数の変態生成物により構成さ れている. 従って,一つの Johnson-Mehl の式のみでマ ルテンサイト量が予即できるとして取り扱っている事に 無理がある。乙の問避を解明する事は将来の荲要テーマ である. 本論文では一つの Johnson-Mehl 式でどの程度 の硬さ予測がなされるかを検討して行く．そこで， $n$ 值 


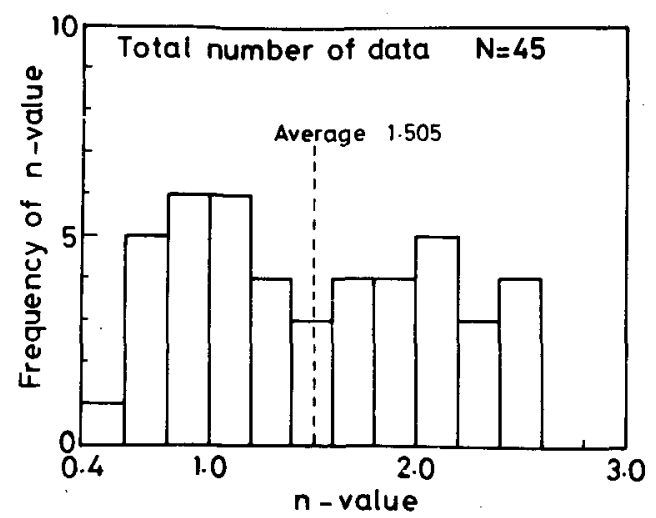

Fig. 3 Frequency distribution of $n$-value

の平均値を求めると

$$
n=1.505
$$

となる.そこで $n=1.5$ を時間指数とする.

(2) マルテンサイト0\%, 100\%の硬さ $H_{V X}, H_{V 0}$

CCT 図より $H_{V K}, H_{V_{0}}$ を読み取り，回帰分析した。

$H_{V \boldsymbol{H}}$ は 102 枚のデータが, $H_{\Gamma_{0}}$ は79枚のデータが CCT 図から得られた。

$$
\begin{aligned}
& H_{\text {VY }}=812 \mathrm{C}+293 \quad\left(R^{2}=71.996\right) \\
& H_{V 0}=293 \mathrm{C}+47 \mathrm{Mn}+48 \mathrm{Si}+44 \mathrm{Cr}+91 \mathrm{Mo}+8 \mathrm{Ni} \\
& +165 \mathrm{~V}+\mathrm{Cu}+95 \mathrm{Nb}+794 \mathrm{~B}+87 \\
& \quad\left(R^{2}=89.3 \%\right)
\end{aligned}
$$

(3) 应散変態生成物が出始める時間 $\tau$

CCT 図からマルテンサイトが95\%となる時間て世を 精度良く求める事は困難であった。 そこで，式(10)と硬さ を利用して次式により :

$$
\tau_{\boldsymbol{H}}=\tau\left[1 / 0.05 \ln \left\{\left(H_{V \boldsymbol{L}}-H_{V_{0}}\right) /\left(H_{V} / H_{V_{0}}\right)\right\}\right]^{-1 / 1.5}
$$

得られた72枚のデータを回帰した結果として次式が逽か れた。

$\log \tau_{M Y}=0.83 \arctan (8 \mathrm{C})+0.64 \mathrm{Mn}+0.38 \mathrm{Ni}$

$+0.73 \mathrm{Cr}+0.76 \mathrm{Mo}+0.65 \mathrm{Cu}+150 \mathrm{~B}-1.505$

$$
\left(R^{2}=78.39\right)
$$

\section{3 硬さ予測式と逼用籍围}

3. 2節をまとめると硬さ予測式として次式が得られる.

$$
H_{\boldsymbol{V}}=\left(H_{V_{X}}-H_{\boldsymbol{V}_{0}}\right) \exp \left\{-0.05\left(\tau / \tau_{\mathbf{K}}\right)^{n}\right\}+H_{V_{0}}
$$

$$
\text { ただし， } H_{V M}=812 \mathrm{C}+293
$$

$H_{V_{0}}=293 \mathrm{C}+47 \mathrm{Mn}+48 \mathrm{Si}+44 \mathrm{Cr}+91 \mathrm{Mo}+8 \mathrm{Ni}$ $+165 \mathrm{~V}+\mathrm{Cu}+95 \mathrm{Nb}+794 \mathrm{~B}+87$

$\log t_{M}=0.83 \arctan (8 \mathrm{C})+0.64 \mathrm{Mn}+0.38 \mathrm{Ni}$ $+0.73 \mathrm{Cr}+0.76 \mathrm{Mo}+0.65 \mathrm{Cu}+150 \mathrm{~B}-1.505$

回率に用いたデータから適用範囲を求めると Table 1 と

\begin{tabular}{|c|c|}
\hline Variable & Range \\
\hline C & $0.04--0.26$ (wt) \\
\hline Si & $0-0.60$ \\
\hline Mn & $0.35 \cdots-1.6$ \\
\hline $\mathrm{Ni}$ & $0-\cdots-2.0$ \\
\hline $\mathrm{Cr}$ & $0 \cdots-1.3$ \\
\hline Mo & $0-\cdots-0.5$ \\
\hline $\mathrm{Cu}$ & $0 \cdots-0.4$ \\
\hline$v$ & $0 \cdots-0.14$ \\
\hline B & $0-0.003$ \\
\hline Nb & $0 \ldots-0.05$ \\
\hline $\mathrm{Ti}$ & $0 \cdots-0.03$ \\
\hline$\tau(=\mathrm{t} 8 / 5)$ & $1-\ldots-100(s)$ \\
\hline
\end{tabular}
なる。

\section{4. 硬さ予测式の棈度の検討}

従来の硬さ予湖式として Becker(6)，Duren ${ }^{11)}$ ，百合

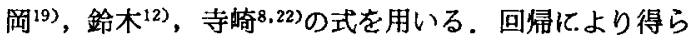
れた予測式の検討には回候に用いなかった硬さのデータ を使用した. Table 2 に今までに報告されている硬さの
Table 1 Applicable range of predictive equation

Table 2 Comparison of predictive equations for maximum hardness in the $\mathrm{HAZ}$

\begin{tabular}{l|r|r|c|c|c|c|c|c}
\hline & SN & N & $D_{T}$ & $D_{S}$ & $D_{Y}$ & $D_{D}$ & $D_{B}$ & $D_{\text {JJN }}$ \\
\hline \hline Vurioka & 14 & 140 & 19.1 & 14.4 & 14.1 & 40.8 & 52.4 & 21.5 \\
Harasawa & 19 & 171 & 29.5 & 33.1 & 31.1 & 54.8 & 64.8 & 34.2 \\
Hart & 3 & 19 & 42.2 & 43.2 & 39.7 & 60.3 & 93.3 & 37.7 \\
Duren & 3 & 18 & 30.0 & 39.5 & 56.2 & 57.3 & 37.5 & 44.0 \\
Evans & 11 & 19 & 21.6 & 23.1 & 24.3 & 23.0 & 29.8 & 31.4 \\
UES & 44 & 278 & 22.2 & 17.6 & 20.6 & 42.4 & 45.7 & 19.7 \\
Ito & 36 & 72 & 23.9 & 24.7 & 29.9 & 36.7 & 33.7 & 36.1 \\
Bessyo & 97 & 97 & 27.2 & 29.8 & 29.1 & 40.6 & 68.9 & 29.2 \\
Ki tada & 91 & 99 & 26.7 & 29.3 & 27.7 & 54.9 & 62.7 & 31.2 \\
Matsuda & 11 & 11 & 22.8 & 41.0 & 45.0 & 96.4 & 66.5 & 26.0 \\
Komi zo & 33 & 40 & 40.7 & 41.4 & 44.0 & 48.8 & 48.9 & 45.1 \\
\hline
\end{tabular}

実測值と予測結果を示す．表中の $D$ は次式に示すよう に実測値 $H_{\boldsymbol{V}}$ と予測值 $\hat{H_{\boldsymbol{V}}}$ の差

$$
D=\sqrt{\left(H_{V}-\widehat{\left.H_{V}\right)^{2} / N}\right.}
$$

ただし，N は硬さのデータの総数

より求められたバラッキを示している，D の添字 $\mathrm{T}, \mathrm{S}$, $\mathrm{V}, \mathrm{D}, \mathrm{B}, \mathrm{JOM}$ は本論文の提案式, 鈴林 ${ }^{12)}$, 百合岡 ${ }^{19)}$, Duren ${ }^{1)}$, Becker $^{6}$, 守猗 ${ }^{8}{ }^{822}$ の式での計算結果を意味 し，SN は使用された鋼の総数を意味する。百合岡の式 はYurioka ${ }^{23)}$ のデータを用いて回㷌されており，鈴木 の式は Yurioka, Hart'24), Duren ${ }^{11)}$, WES ${ }^{25)}$ のデータ を用いて回㷌されている。従って，当然の事であるが Yurioka, WES のデータの $D_{Y}, D_{S}$ は今回求められた式 による $D_{T}$ よりも優れている. それ以外の Harasawa ${ }^{26)}$, Evans $^{27)}$, l(to ${ }^{28)}$, Bessyo ${ }^{5)}$, Kitada ${ }^{29)}$, Matsuda ${ }^{30)}$, Komizo ${ }^{31)}$ のデータでは今回求めた式による $D_{r}$ が一番優 れている。

Fig. 4(a)，(b) 亿百合岡が測定した硬さのデータと本 論文で提案する式(12および著者の一人が以前に提案した 予椡式 JOM の計算値を示す。今回の提案式が実測の硬 さを精度良く予测している。

Table 3 は Table 2 の硬さのデータを銅種別に分類し たときのバラッキD示している，鋼種の分類は次の 様比しいる。

(1) $\mathrm{Cr}, \mathrm{Ni}, \mathrm{Mo}, \mathrm{Cu}$ が 0.1 wt 


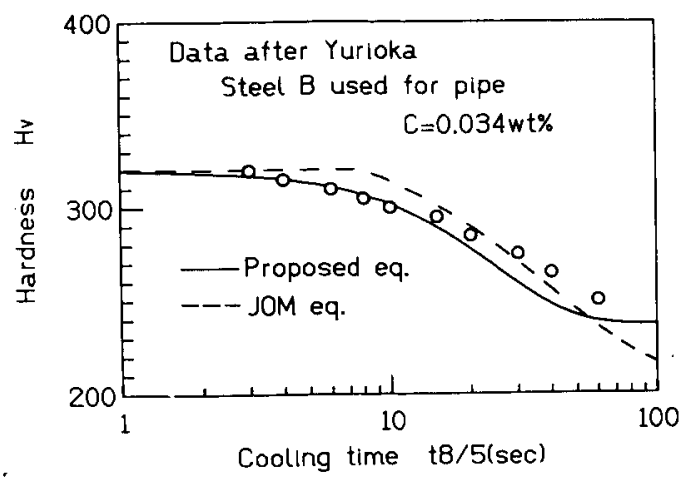

(a) Steel B

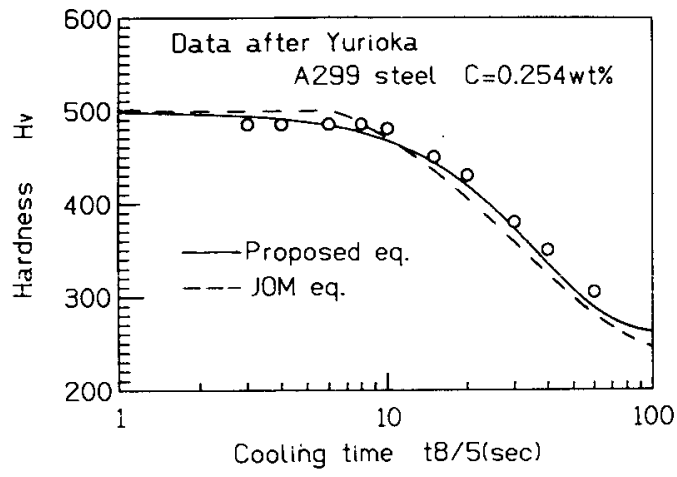

(b) A299 Ste.e.

Fig. 4 Comparison between measured hardness and estimated value

Table 3 Comparison between deviations of estimaiting hardness classified by the kinds of steel

\begin{tabular}{|c|c|c|c|c|c|c|c|c|}
\hline & SN & N & DT & $D_{s}$ & Des & $D_{0}$ & $D_{B}$ & Djon \\
\hline $\begin{array}{l}\text { C-Mn steel } \\
\text { with } \mathrm{Cr}, \mathrm{Ni}, \mathrm{Mo}_{0}<0.1 \%\end{array}$ & 113 & 311 & 28.8 & 29.8 & 31.2 & 41.0 & 62.5 & 29.8 \\
\hline $\begin{array}{l}0.1 \%<\mathrm{Cr}, \mathrm{Ni}, \mathrm{Mo} \\
<1 \% \text { steel }\end{array}$ & 143 & 442 & 26.2 & 26.3 & 26.3 & 39.5 & 57.9 & 28.7 \\
\hline$C<0.1 \%$ steel & 78 & 194 & 21.6 & 22.0 & 24.6 & 32.6 & 31.5 & 31.5 \\
\hline Cr-Mo steel & 30 & 87 & 26.8 & 27.6 & 26.8 & 89.5 & 42.1 & 35.0 \\
\hline $\begin{array}{l}\mathrm{C}>1 \mathrm{X} \text { or } \mathrm{Ni}>1 \mathrm{X} \\
\text { or Mo>1X steel }\end{array}$ & 44 & $\mathbf{9 0}$ & 22.8 & 22.4 & 23.2 & 93.4 & 45.3 & 23.3 \\
\hline
\end{tabular}

wt $\%$ である炭素マンガン銅

(2) $\mathrm{C} \geqq 0.1$ wt\% で Crまたは Niまたは Moまたは $\mathrm{Cu}$ が $0.1 \sim 1$ wt $\%$ 含有されている鋼

(3) C ts 0.1 wt $\%$ 以下で $\mathrm{Ni}<0.5 \mathrm{wt} \%, \mathrm{Cr}<0.1$ wt $\%, \mathrm{Mo}<0.25 \mathrm{wt} \%$ である鋼，多くの TMCP 鈮がこ の成分範囲にある。

(4) $\mathrm{Cr}-\mathrm{Mo}$ 鎆

(5) $\mathrm{Cr}$ または Ni または Mo が 1 wt\% 以上含まれ ている鉠

以上の分類された鋼種の $D$ を比較してむ，今回導か れた硬さ予测式は精度の良い式である事が分かる。

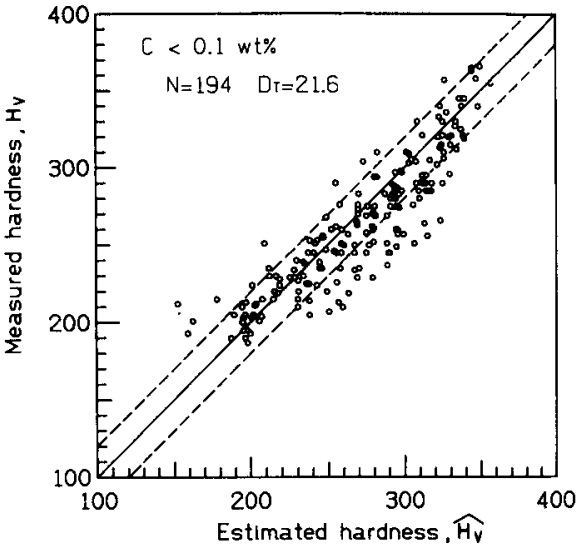

(a)Proposed equation

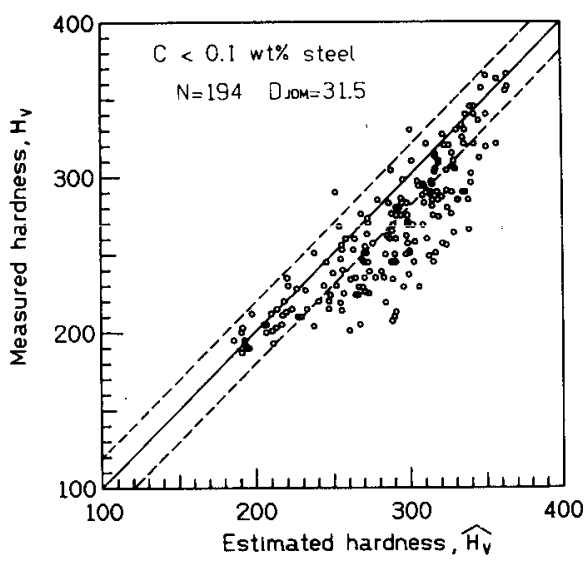

(b). I0M equation

Fig. 5 Measured hardness vs. estimated hardness

Table 4 Evaluation for steels with carbon content excluding applicable range

\begin{tabular}{l|r|c|c|c|c|c|c|c}
\hline & SN & N & $D_{T}$ & $D_{S}$ & $D_{Y}$ & $D_{0}$ & $D_{B}$ & $D_{\text {JOM }}$ \\
\hline C $>0.3 \%$ steel & 7 & 12 & 65.0 & 51.5 & 74.2 & 75.4 & 54.6 & 51.6 \\
C<0.04\% steel & 28 & 65 & 23.5 & 24.9 & 31.6 & 45.2 & 32.2 & 37.0 \\
\hline
\end{tabular}

Fig. 5(a)，(b) に上部の分類(3)の硬さの実測值と予测 值を示す。令回提案した式の精度が上いことが分かる。

Table 4 は Table 1 の適用範国外にある銅を用いた時 のバラッキ $D$ 值を示している. 表より $\mathrm{C}>0.3$ wt $\%$ の 鋼には今回の提案式は使用できないことが分かる。

\section{5 . 結}

論

本論文で得られた結論を要䄪すると次のようになる。

1）変態速度論を用いて導かれた硬さ予測式(12)は熱影 帮部の硬さを精度良く予测した。乙の事は治金の研究成 果を用いて硬さ変化曲楾を導く手法が他の筆なる仮定式 を用いる手法よりす優れている事を意味していると思わ れる。

2）導かれた予测式は炭素マンガン鎡，低炭素鋼， $\mathrm{Cr}$-Mo 鎆の硬さを精度良く予測した。 
3）適用範围外の C >0.3 wt\% の鎆の硬さ予測には 今回導かれた予測式は適していなかった。

\section{参 考 文 献}

1) F. R. Coe: Welding Steels without Hydrogen Cracking, TWI, 1973

2) P. J. Haagensen: TIG Dressing of Steel Weldments for Improved Fatigue Performance, 1979, 11th OTC, p.949

3) J. Dearden and H. O'neil: A Guide to the Selection and Welding of Low Alloy Structural Steels, Trans. Inst. Welding, 1940, No.10, p.203

4) H. Suzuki and H. Tamura:Synthetic Heat-Affected Zone Ductility Test, Trans. National Research Institute for Metals, Vol.1, No.2, 1959, p.42

5) Y. Ito and K. Bessyo: Weldability Formula of High Strength Steels, IIW, Doc. IX-576-68, 1968

6) $M$. Beckert and R. Holz:Schweiss Technik, Vol.23, 1973, No.8, p.344

7) Y. Arata, K. Nishiguchi, T. Ohji, N. Kohsai and M. Tomie: Weldability Concept of Hardness Prediction, IIW Doc. IV-263-72

8）寺畸俊夫：溶接部の低温割れに関係する熱因子および硬度の推定 式の検討，鉄と鎆、Vol.67, No.16, 1981，p.2715

9) N. Yurioka, S. Ohshita and H. Tamehiro: Study on carbon Equivalents to assess Cold Cracking Tendency and Hardness in Steel Welding, AWRA Symposium “Pipeline Welding in the 80's", March, 1981

10) P. Seyffarth: Schweiss Technik, Vol.27, 1977, No.2, p.58

11) K. Lorenz and C. Duren : C-Equivalent for Evaluation of Weldability of Large-Diameter Pipe steels, IIW, Doc. IX-B-11-82, 1982

12) H. Suzuki : A New Formula for Estimating HAZ Maximum Hardness in Welded Steel, IIW, Doc. IX-1351-85, 1985

13) M. A. Grossmann : Elements of Hardenability, ASM, 1952

14) H. Umemoto, N. Komatsubara and I. Tamura: Prediction of Hardenability Effects from Isothermal Transformation Kinetics, J. Heat Treating, Vol.1, No.3, p.57

15) J. Burke: The Kineties of Phase Transformation in Metals, Pergamann Press, 1965

16) M. Inagaki and T. Wada : A New Apparatus for Determining SH-CCT Diagram for Welding and its Application to High Strength Steels, Trans. National Research Institute for Metals, Vol.6, No.1, 1964, p.39

17）稻垣道夫：本誌, Vol.29, No.8，No.10；金材研技報，Vol.4 (1961)-No.5, Vol.11 (1968)-No.2, Vol.12 (1969)-No.4, Vol.14(1971)-No.3, Vol.18(1975)-No.2 ; CCT-Diagrams, Nippon Steel Corporation, 1972

18) J. S. Kirkldy : Met. Trans., Vol.4 (1973),. p.2327

19) E. Scheil : Arch. Eiserhuttenw., Vol.12 (1935), p.565

20) C. M. Adams: Cooling Rates and Peak Temperature in Fusion Welding, Welding Journal Vol.37, No.5, June, $1958,210 \mathrm{~s}$

21) N. R. Draper and H. Smith : Applied Regression Analysis, John Wiley Sons, 1966

22) T. Terasaki, T. Akiyama and M. Serino: Chemical Compositions and Welding Procedure to Avoid Cold Cracking, Proc. Intl. Conf. Joining of Mrtals, April, 1984, Helsingor, Denmark, p.381

23) N. Yurioka, M. Okumura and S. Saitoh: JWS Weld. Met. Comm., WM-784-80, 1980

24) P. H. M. Hart: A Preliminary Evalution the Effect of Restraint on HAZ Cold Cracking of Butt Welds in Three C-Mn steels, TWI Report 40, 1977
25）WES：日本溶接協会，鈴木春義先生よりデータを顶載する。（私信）

26）原沢秀明：（私信） 1982

27) G. M. Evans and Christensen: Correlation of Microstructure with HAZ Embrittlement, IIW, Doc. IX-823-73

28) Y. Ito, M. Nakanishi and Y. Komizo : Carbon Equivalent and Hardness for Cracking Tendency of $\mathrm{C}-\mathrm{Mn}$ Microalloyed Structural Steel, IIW, Doc. IX-1349-85, 1985

29) T.Kitada and J.Tanaka: Trans.of JIM, 1980; JWS Weld. Met. Commi. WM-743-80, 1980

30) F. Matsuda and H. Nakagawa: Trans. JWRI, Vol.7 (1978), p.47

31) Y. Ito, M. Nakanishi and Y. Komizo: Trans. of JIM, 1980

\section{付䟿 従来の硬さ予測式}

(1) Becker $の$ 式 ${ }^{6}$

$H_{V}=\left(H_{V \Perp}-H_{V_{0}}\right) \exp \left[-(b \tau)^{2}\right]+H_{V_{0}}$

ただし， $H_{V A r}=939 \mathrm{C}+284, H_{V_{0}}=167$

$(\mathrm{C}+\mathrm{Si} / 11+\mathrm{Mn} / 2.9+\mathrm{Cu} / 3.9+\mathrm{Ni} / 17+\mathrm{Cr} / 3.2$

$+\mathrm{Mo} / 2.4)^{2.42}+137$

$b=\exp \left(-0.013 H_{\mathrm{V}_{0}}+0.8\right)$

(2) 寺畸の式 8 ,22)

$$
\begin{array}{ll}
\tau \leqq \tau_{M} & H_{\boldsymbol{V}}=H_{V_{M}} \\
\tau \tau_{M} & H_{V}=\left(H_{V_{M}}-H_{V_{0}}\right) \exp \left[-0.2\left(\tau / \tau_{M}-1\right)\right] \\
& +H_{V_{0}}
\end{array}
$$

ただし, $H_{V A}=812 \mathrm{C}+293, H_{V_{0}}=164$

$(\mathrm{C}+\mathrm{Si} / 2+\mathrm{Cr} / 7+\mathrm{Mo} / 2+\mathrm{V}+\mathrm{Nb}+7 \mathrm{~B})+153$, $\log \left(\tau_{M}\right)=2.5(\mathrm{C}+\mathrm{Mn} / 3+\mathrm{Cu} / 4+\mathrm{Ni} / 8+\mathrm{Cr} / 10$ $+\mathrm{Mo} / 3+5 \mathrm{~B})-1.27$

(3) 百合岡の式 ${ }^{93}$

$H_{V}=\left(H_{V M}+H_{V 0}\right) / 2-\left(H_{V M}-H_{V M}\right) / 2$.

$[\arctan (X) / 1.10]$

ただし， $X=4\left[\log (\tau)-\log \left(\tau_{M}\right)\right] /\left[\log \left(\tau_{0}\right)\right.$

$\left.-\log \left(\tau_{M}\right)\right]-2, H_{V M}=812 \mathrm{C}+293, H_{V_{0}}=328$

$(\mathrm{C}+\mathrm{Si} / 24+\mathrm{Mn} / 6+\mathrm{Cu} / 15+\mathrm{Ni} / 40+\mathrm{Cr} / 6$

$+\mathrm{Mo} / 4+\mathrm{Nb} / 5+\mathrm{V} / 5+10 \mathrm{~B})+72$

$\log \left(\tau_{M}\right)=7.4 \mathrm{CEY}-3.027, \log \left(\tau_{0}\right)$

$=5.6 \mathrm{CEY}+1.821 \quad \mathrm{CEY}=\mathrm{C}-\mathrm{Si} / 30+\mathrm{Mn} / 5$

$+\mathrm{Cu} / 5+\mathrm{Ni} / 20+\mathrm{Cr} / 4+\mathrm{Mo} / 6+10 \mathrm{~B}$

(4) Duren $の$ 式11)

$$
\begin{aligned}
& H_{V}=2019[\mathrm{C}\{1-0.5 \log (\tau)\}+0.3(\mathrm{CED}-\mathrm{C})] \\
& \quad+66[1-0.81 \log (\tau)] \\
& \text { ただし, CED } \mathrm{C}+\mathrm{Si} / 11+\mathrm{Mn} / 8+\mathrm{Cu} / 9+\mathrm{Ni} / 17 \\
& \quad+\mathrm{Cr} / 5+\mathrm{Mo} / 6+\mathrm{V} / 3
\end{aligned}
$$

(5) 鈴木の式 22

$$
\begin{aligned}
& H_{V}=H_{V^{r} 0}+\left(H_{V M}-H_{V_{0}}\right) /[1+\exp \{a[\log (\tau) \\
& \left.\left.\left.\quad-\log \left(\tau_{50}\right)\right]\right\}\right] \\
& \text { ただし, } H_{V M}=884 \mathrm{C}+287, H_{V 0}=430 \mathrm{C}+36 \mathrm{Si} \\
& \quad+79 \mathrm{Mn}+57 \mathrm{Cu}+12 \mathrm{Ni}+53 \mathrm{Cr}+122 \mathrm{Mo} \\
& \quad+169 \mathrm{Nb}+7089 \mathrm{~B}+18, \\
& \quad \log \left(\tau_{50}\right)=2.07 \mathrm{C}+0.459 \mathrm{Mn}+0.655 \mathrm{Cu} \\
& \quad+0.122 \mathrm{Ni}+0.222 \mathrm{Cr}+0.788 \mathrm{Mo}+30 \mathrm{~B}-0.085, \\
& a=(478+3364 \mathrm{C}-256 \mathrm{Si}+66 \mathrm{Ni}-408 \mathrm{Mo} \\
& \quad-1321 \mathrm{~V}-1559 \mathrm{Nb}) /\left(H_{V_{M}}-H_{r^{\prime} 0}\right)
\end{aligned}
$$

